\title{
Spatial distribution of the effect of temperature \&rainfall on the production of BoroRice in Bangladesh
}

\author{
Md. Abu ZaferSiddik, Abu Sufian Mohammad Asib, Samrin Ahmed Kusum \\ Post Graduate Student, Department of Civil \& Environmental Engineering, Bangladesh University of Engineering and Technology, \\ Dhaka-1000, Bangladesh
}

\section{Email address:}

zafersiddik@gmail.com (Md. A. ZaferSiddik),asib.asm.ce@gmail.com (A. S. M. Asib),samrin06kusum@gmail.com (S. A. Kusum)

\section{To cite this article:}

Md. Abu ZaferSiddik, Abu Sufian Mohammad Asib, Samrin Ahmed Kusum. Spatial Distribution of the Effect of Temperature \&Rainfall on the Production of Bororice in Bangladesh. American Journal of Remote Sensing. Vol. 1, No. 4, 2013, pp. 88-95.

doi: 10.11648/j.ajrs.20130104.13

\begin{abstract}
Climate is one of the major controlling factors for the well-being of the residents in the world. Global climate has been changing due to natural forces as well as anthropogenic activities, especially for emissions of greenhouse gases, aerosols and land use changes in recent decades. Climatic factors such as temperature, rainfall, relative humidity, cloud coverage, wind speed, bright sunshine etc. are closely linked with agricultural production. This paper mainly focuses on the effect of rainfall \& temperature on the production of Boro rice. Rice production has been a major concern in recent years due to changing climatic conditions because significant amount of rice yield may be hampered for fluctuations in those climatic parameters. This study is limited to assess the effect of climate change on production of Boro rice in Bangladesh. Boro cultivation is held on dry season (mostly November-April in Bangladesh). Geographic Information System (GIS) is a tool to show the spatial distribution of the effect of these climatic parameters on the production of Boro in Bangladesh. This effect is shown by normalization of Boro yield by temperature and rainfall.
\end{abstract}

Keywords: Geographic Information System (GIS), BoroRice, Crop Yield, Temperature, Rainfall

\section{Introduction}

Bangladesh is an agriculture-based country with 76 percent of total population living in the rural areas and 90 percent of the rural population directly related to agriculture (Mondal MH, 2010). Increasing food production and attaining food security in Bangladesh require sustainable growth of agricultural sector. The AgroEconomic contribution is 20.83 percent of the Gross Domestic Product (Bangladesh Economics Review, 2009). But this sector is under pressure and vulnerable to climate change. Since rice is the principal food in Bangladesh and Boro rice is one of the varieties, it is very important to identify the effects of climate change on the production of Boro rice so that food security can be ensured. There are many parameters that altogether conform to the concept of Climate Change. Some hydro-meteorological parameters are rainfall, temperature, humidity, solar radiation, wind velocity, cloud coverage, bright sunshine etc. (Ahmed, A. and Ryosuke, S. 2000). There are also physico-chemical parameters like Green House Gases (GHGs), aerosol emissions etc. Climate Change is a broad term which refers to the variation of statistical distribution of different parameters for a long period of time, usually starting from 40 years. In this study, only those climatic parameters were chosen that has a direct impact on crop production and the selected climatic parameters are temperature \& rainfall. It should be noted that there are some other climatic parameters as well that can affect the Boro rice production. Also there are soil characteristics that have been neglected in this research.

Boro cultivation is becoming more popular day by day because of introduction of some High Yielding Varieties (HYVs) to the farmers and advanced irrigation techniques and irrigation water management. These varieties are resistant to pest attacks and adaptive to salinity. That is why Boro cultivation is applicable anywhere in Bangladesh (Choudhury, M. 2004). Thus elaborate research on this type of rice cultivation is essential for ensuring food security for increasing demand of evergrowing population.

Another aspect of this study is the incorporation of GIS in the visualization of changes that are occurring spatially and as well as temporally. Geographic Information System (GIS) is a useful tool to input, store, retrieve, manipulate, analyze and output geographically referenced data or 
geospatial data in order to support decision making for burning issues like climatic changes. In this study, an effort has been given for analysis of data of some climatic parameters and Boro rice yield and to use GIS for the visualization of such changes.

\section{Study Area}

In This study, Bangladesh was divided into twenty three regions and those regions were considered as the study area. Whole Bangladesh was considered in this study because Boro rice is produced all over the country unlike Aus rice. Data of two climatic parameters were collected from 32 weather stations located at Dinajpur, Rangpur, Rajshahi, Bogra, Mymensingh, Sylhet, Srimangal, Ishurdi, Dhaka, Comilla, Chandpur, Jessore, Faridpur, Madaripur, Khulna, Satkhira, Barisal, Bhola, Feni, Maijdee Court, Hatiya, Sitakunda, Sandwip, Chittagong, Kutubdia, Cox's Bazar, Teknaf, Rangamati, Patuakhali, Khepupara, Tangail, Mongla in Bangladesh. And crop yield data of Boro rice was collected from 23 regions of Bangladesh. Among these regions, there were some points where climate parameter data were not available. In that case, the nearest weather station data were used for the purpose of analysis. Figure 1 shows the study area considered in this study.

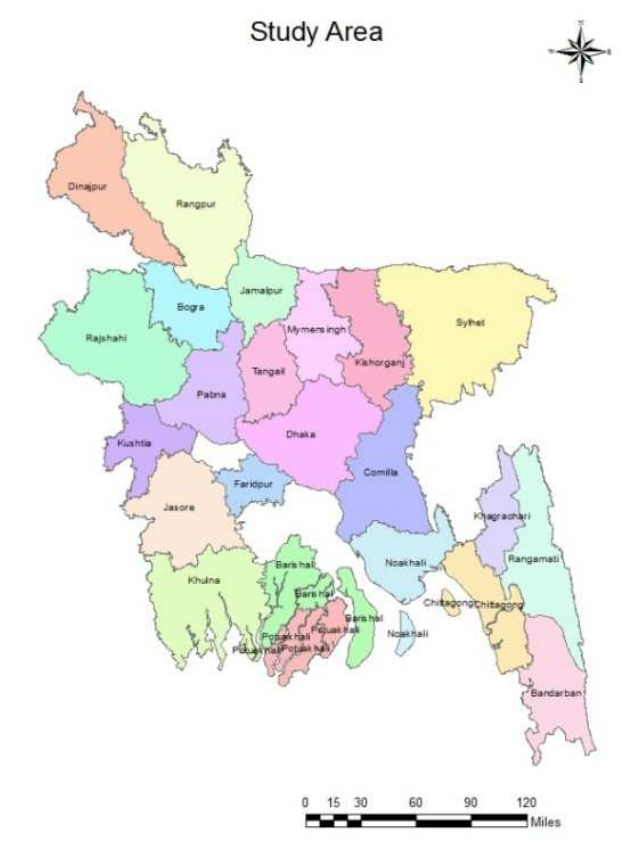

Figure 1: Study Area (Twenty Three Regions of Bangladesh)

\section{Data Collection and Sources of Data}

In this study, wide ranges of data were collected on monthly temperature \& rainfall. Also the regional cultivation area and quantity of Boro rice production in each region were also collected. From all these data, annual average climatic parameter values were found and annual yield of Boro rice was also calculated.

Rainfall (daily) and temperature (maximum and minimum daily) data from 1971-2008 were collected from Bangladesh Meteorological Department (BMD) and Bangladesh Rice Research Institute (BRRI) for all 32 stations. On the other hand, Boro Rice yield (seasonal data, Metric Ton/Hectare) data for 23 regions were collected from Bangladesh Bureau of Statistics (BBS).

\section{Analysis \& Discussion}

November-April is the production period of Boro rice. Crop yield was measured in terms of metric ton/hactre which was calculated by dividing the boro rice production (metric ton) by total cultivated area (hactre). Geographic Information System (GIS) is a tool that was used to delineate the spatial distribution of the effect of temperature and rainfall on crop yield. To delineate this, all maps were created by digitizing and geo-referencing from the google map incorporated with the 23 regional maps (shape file) of Bangladesh.

\subsection{Historical Analysis of Temperature}

Temperature is an important parameter of climate change because it has direct effect on the climate as well as crop production in both short term and long term.Figure 2 shows the distribution of temperature from 1971 to 2008 over the selected twenty three regions:

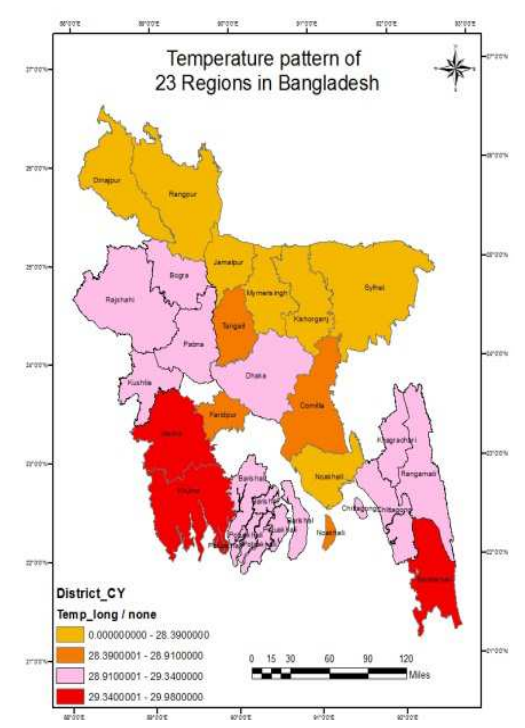

Figure 2: Long term temperature over the twenty three regions of Bangladesh.

From the above figure, it is seen that the hottest regions of Bangladesh are Khulna, Jessore and Bandarban where the temperature varies from $29.3{ }^{\circ} \mathrm{C}$ to $30^{\circ} \mathrm{C}$. The northern, eastern and central parts of the country are cooler than the southern and western parts. 

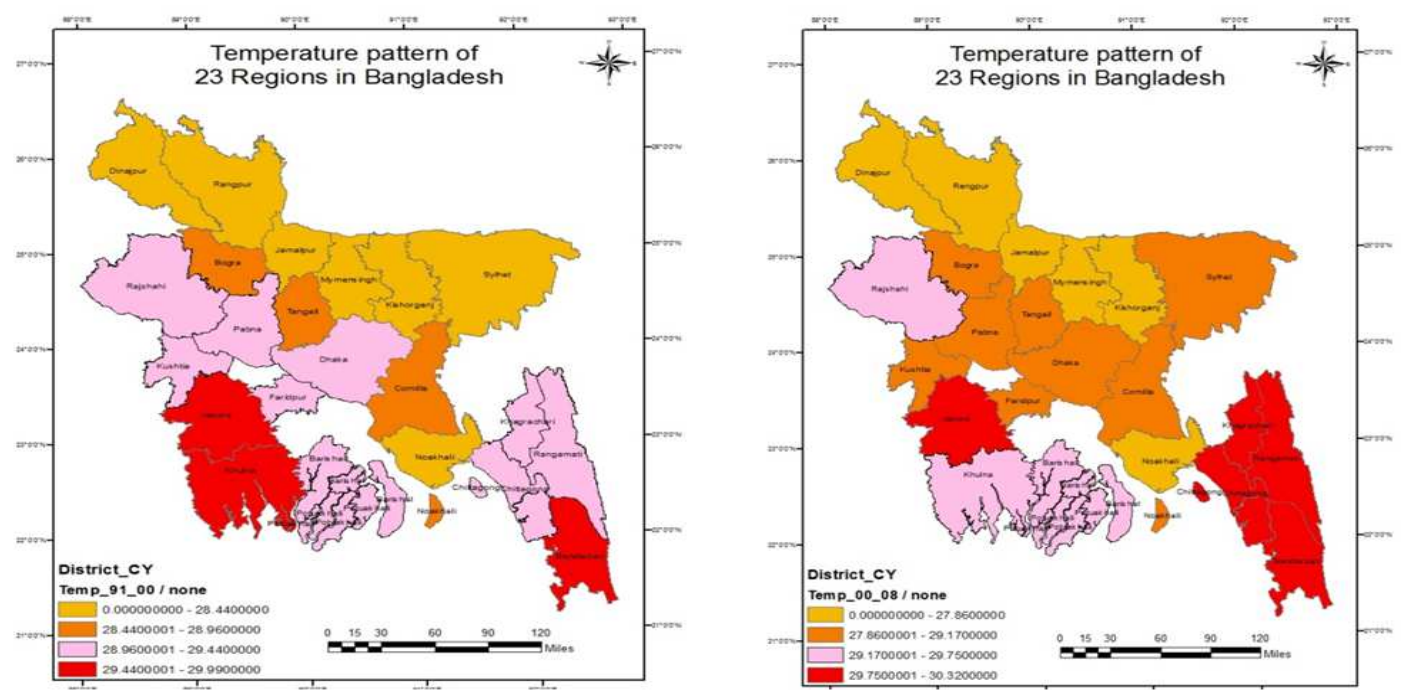

Figure 3: Temperature variation 1971-80 and 1981-90
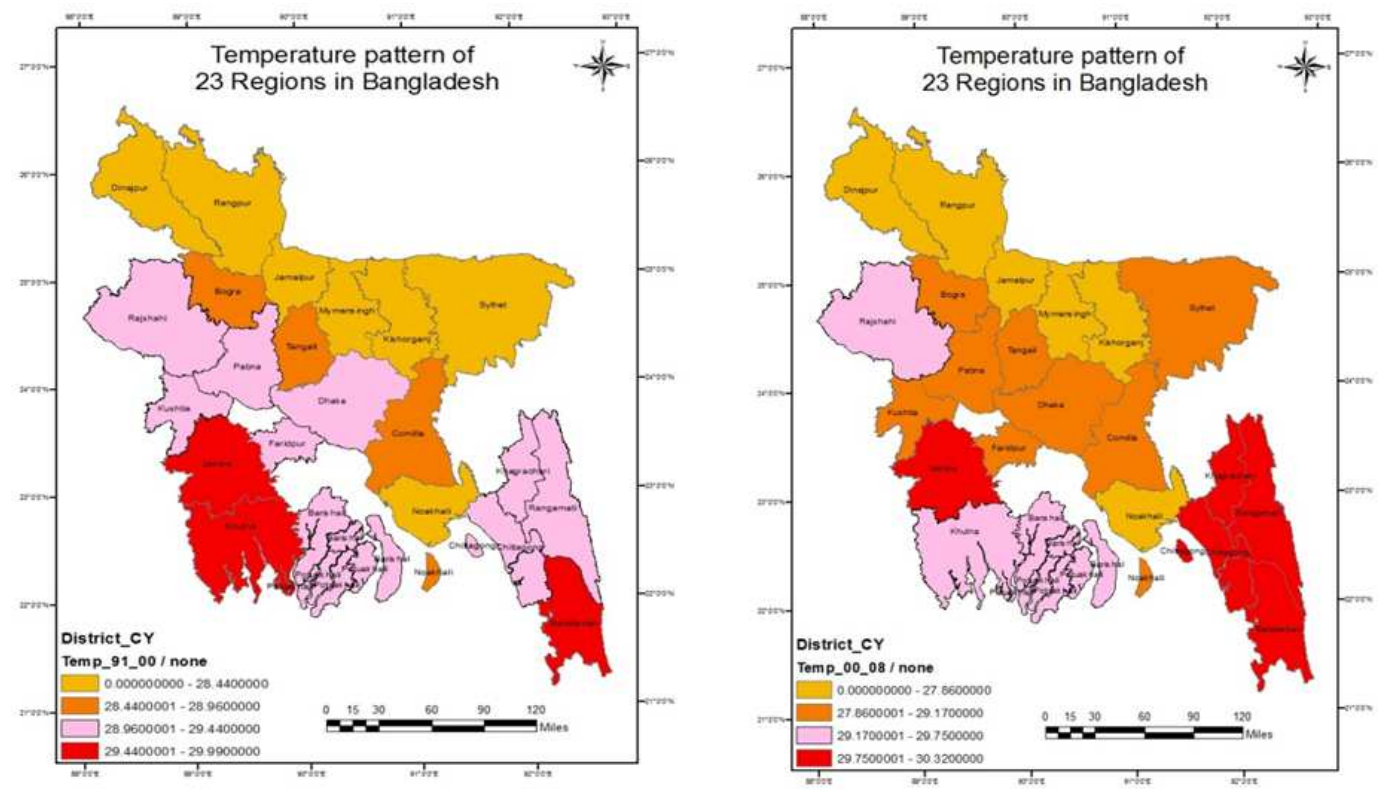

Figure 4: Temperature variation 1991-00 and 2000-08

The images given above shows variation of distribution pattern of temperature at different time periods. Overall observation shows that the hottest places over 37 years are Khulna and Bandarban regions. The time periods are 20082000, 2000-1991, 1990-1981, 1980-1971.It is seen that by this span of time, the temperature hotspot has slowly shifted to the southeast region from the western region. It shows that in the major part of the country, the temperature fluctuates between $28.9^{\circ} \mathrm{C}$ to $29.3^{\circ} \mathrm{C}$. From 1971 to 1980 , the western region of the country was the hottest part. But over the years, the hotspot has shifted more to the east. In recent times (2001-08), the predominant temperature in the central part lies between $28.39^{\circ} \mathrm{C}$ to $28.91^{\circ} \mathrm{C}$. Comparing between the long-term and other short-term periods, it is seen that the long-term average is somewhat similar to the pattern of 1991-2000. Only the Khulna region has remain constantly the hotter region in most of the time periods.
And the northern and central part have come gradually cooler. The Sylhet region has always been the coolest area. The Chittagong Hill Tracts region shows a mixed characteristics over these time periods. The temperature zoning is shown by four colors. The more the temperature, the deep is the color. So, a rough idea can be obtained by viewing the maps.

Over the years, temperature is increasing globally due to urbanization, industrialization, emission of GHGs. The above figures show the variation of temperature in Bangladesh. As Bangladesh cover a tiny area in the world, the broad picture is difficult to depict.

\subsection{Historical Analysis of Rainfall}

Another climatic parameter that affects crop yield is rainfall. This is a vital parameter which determines the 
amount of water needed for irrigation. Since Boro rice is an irrigated crop, rainfall characteristics has a great impact on its production. Here in this study, variation of seasonal rainfall over the twenty three regions of Bangladesh was mapped dividing 40 years into four decades. Rainfall contributes to the consumptive use of the crop.

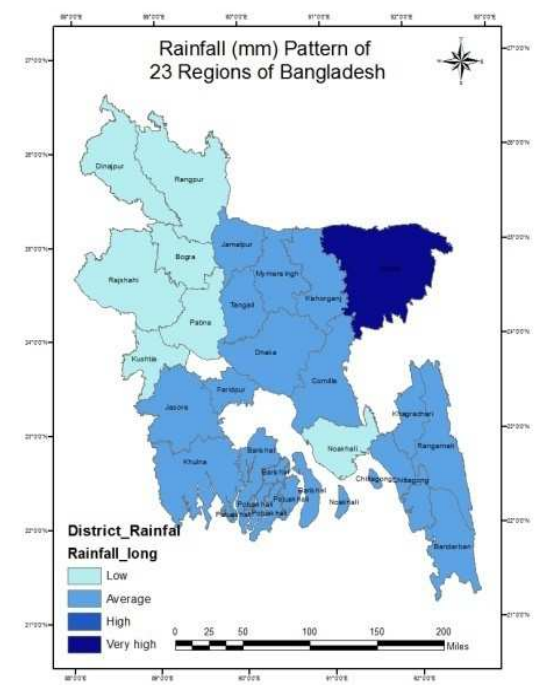

Figure 5: Long term rainfall over the twenty three regions of Bangladesh.

It adds to the irrigation water and ensures growth of the plant. When irrigation water is scarce, rainfall comes as a

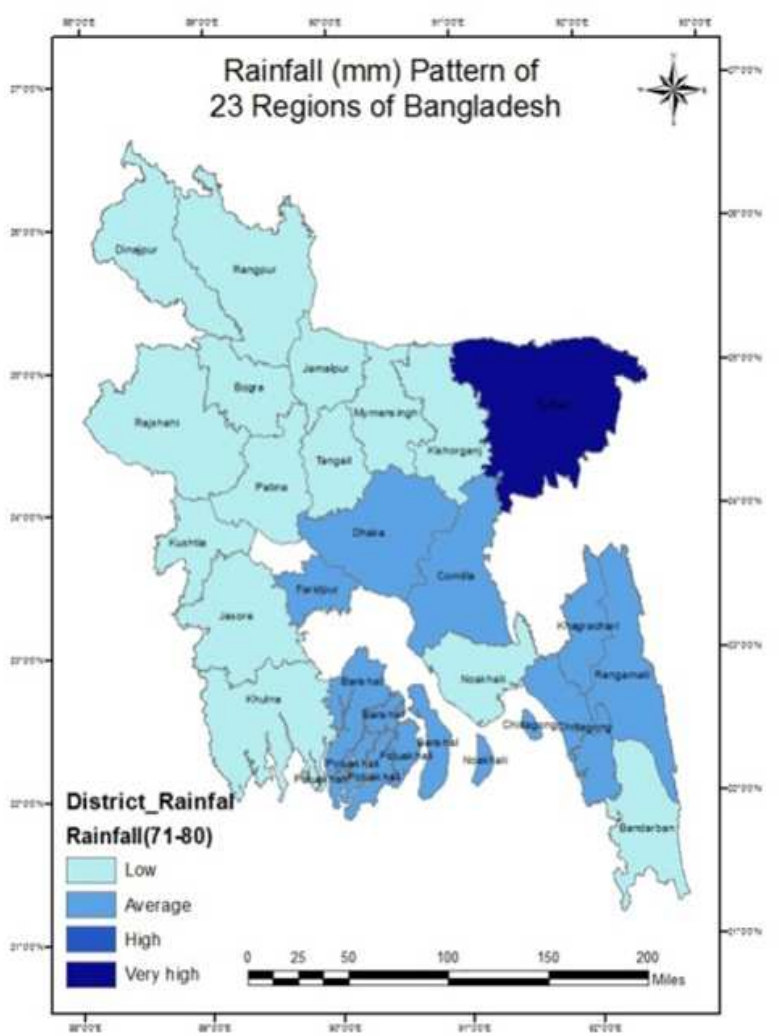

blessing. Due to the geographical position, Bangladesh gets plenty of rainfall in the monsoon period. The following figure shows the long term rainfall pattern from 1971 to 2008 on the study area.

From the above figure, it is seen that the Sylhet region has the maximum long term rainfall in Bangladesh. The whole north-west part of the country gets minimum rainfall. Noakhali region surprisingly gets low rainfall whereas the Chittagong and Comilla regions adjacent to it get high amount of rain.

From the below maps, it is visible that in the 1971-1980 decade, Sylhet region has experienced very high rainfall and except Noakhali and Bandarban, all other south-eastern regions have average rainfall ranging from 30 to $55 \mathrm{~mm}$. But during the year 1981-1990, rainfall increased and most of the zones with low rainfall became regions of average rainfall, whereas Dhaka and Faridpur along with Chittagong, Bandarban regions became regions of high rainfall. Year 1991-2000 follows almost same trend of rainfall pattern and in some regions (Pabna, Kushtia and Jessore) rainfall decreased from average to low. But in recent years, it is quite visible that rainfall reduced all over the 22 regions except Sylhet, where the rainfall was high throughout this 40 years' time frame.After that, the rainy area is increasing and almost three-fourth of the area is under rainy area after 2008.

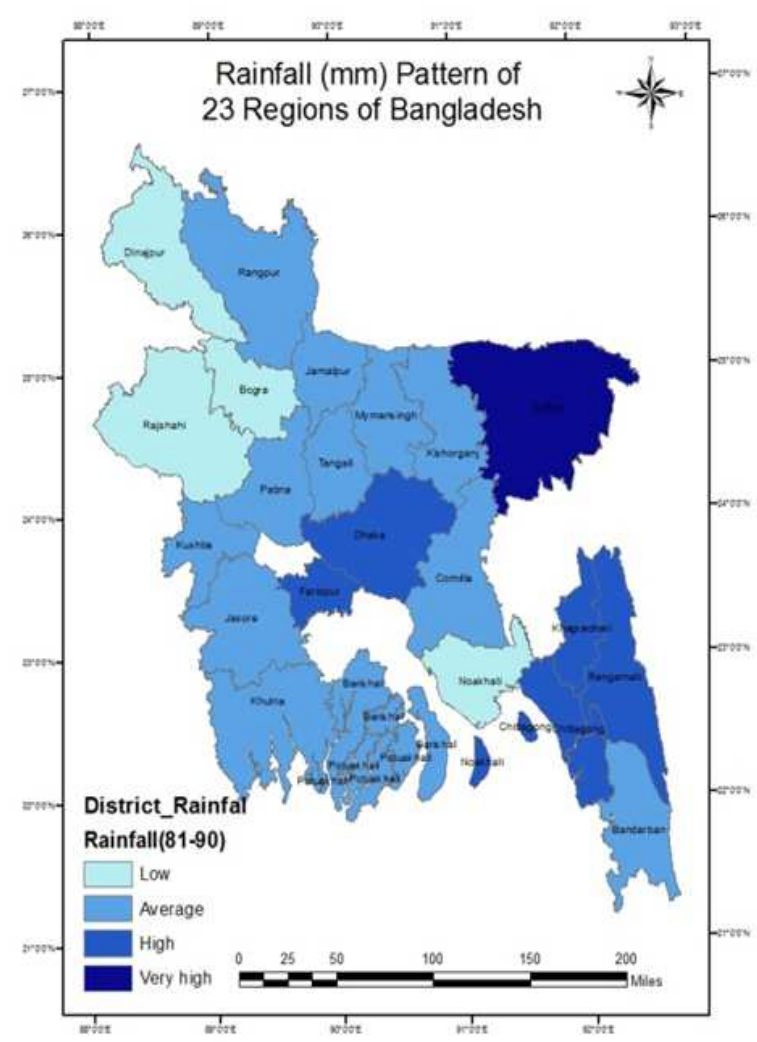

Figure 6: Rainfall variation 1971-80 and 1981-90 


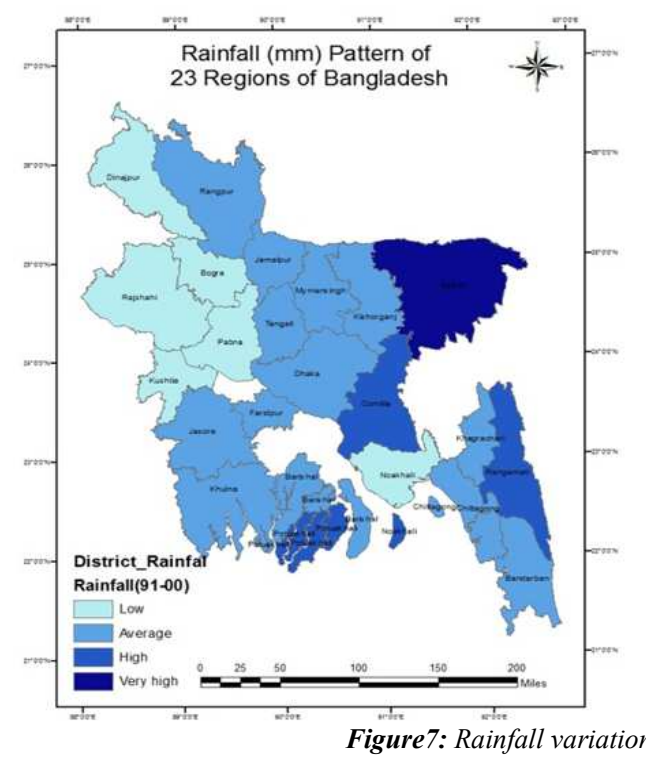

Figure7: Rainfall variation during 1991-00 \&2000-08

\subsection{Historical Analysis of Crop Yield}

Apart from the climatic parameters variation, Boro rice yield variation over the selected 23 regions was also mapped using GIS for the previous 40 years period. The following figures show the variation of Boro rice yield over 40 years period divided into 4 decades.

The previous figure shows the long term variation of crop yield and an overview of boro rice production from 1971-2008 can be found from this map. This map shows that the coastal regions, Rangamati and Noakhali regionsproduce small amount of Boro rice compared to the other regions of this country. While Rajshahi, Jessore, Faripur, Pabna, Tangail and Bogra are the places where Boro rice production is very high compared to other places.

The following shows that, during 1971-1980, Dinajpur, Jessore, Faridpur, tangail, Chittagong produced high amount of Boro rice and the yield ranged from 2.36 to 2.73 M.Ton/Hectare whereas the north-eastern part of Bangladesh including Noakhali and Khulna had small amount of Boro rice production. In the recent time, boro

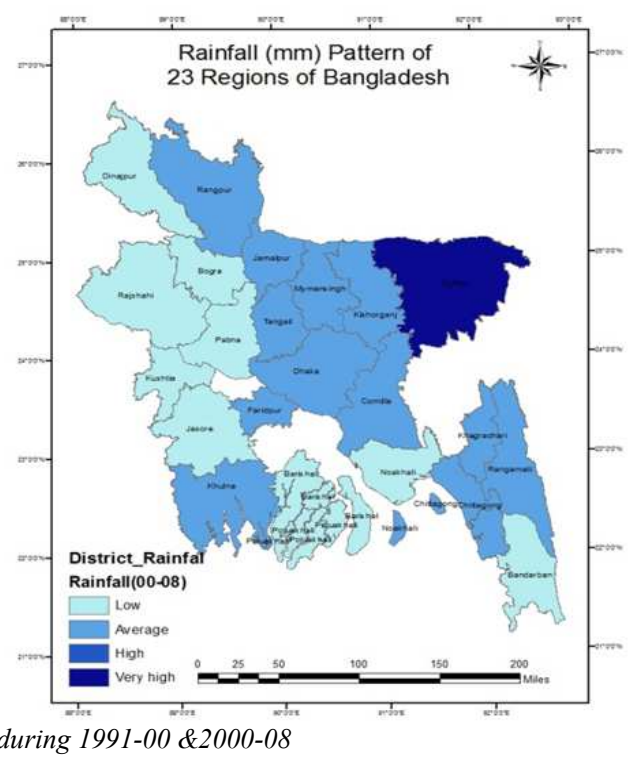

production increased and the yield ranges from 3.14 to 3.86 M.Ton/Hectare.

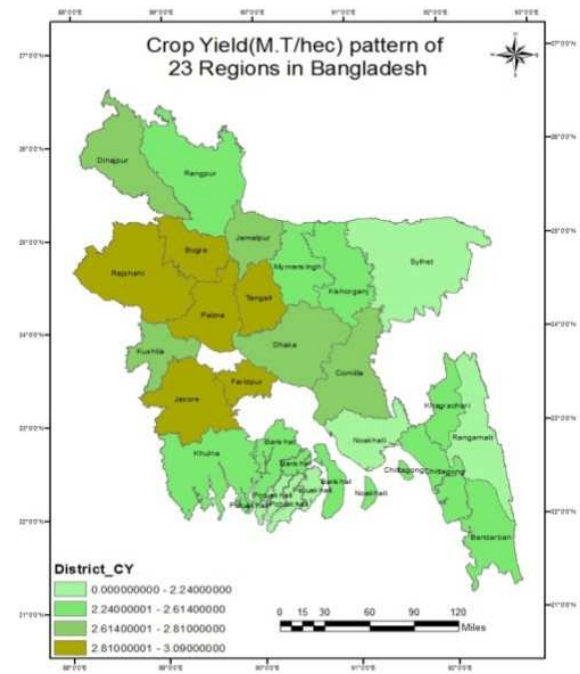

Figure 8: Long term Boro Rice Yield over the twenty three regions of Bangladesh.

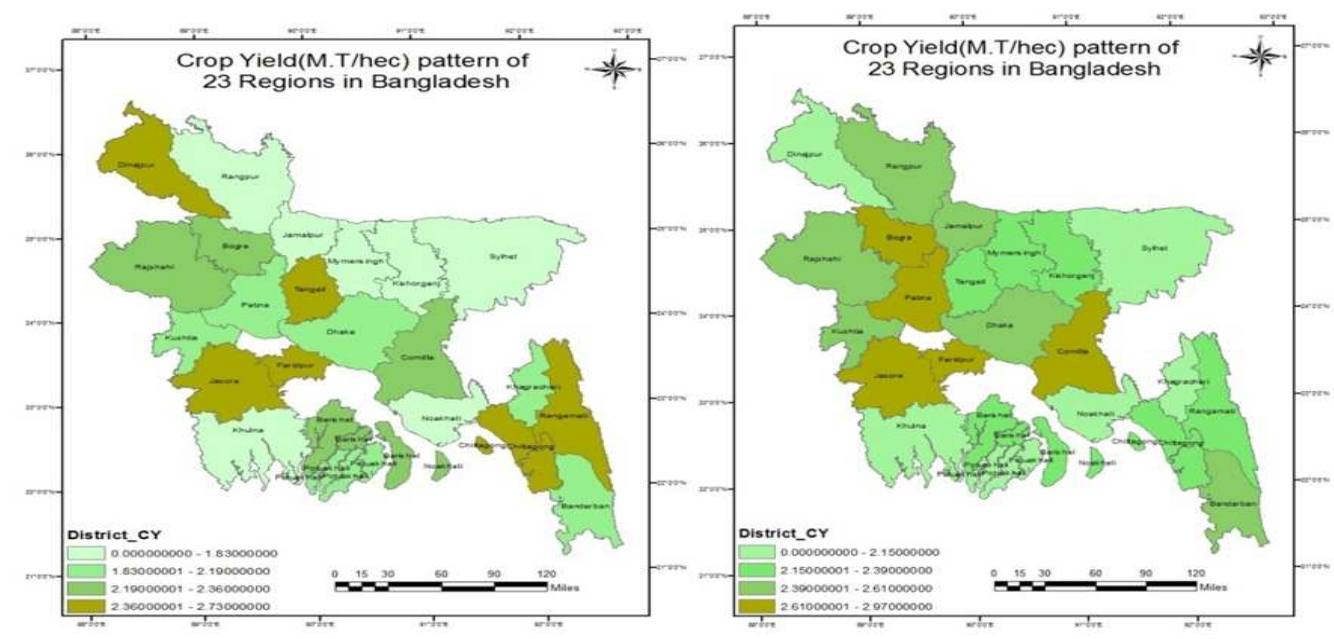

Figure 9: Boro Rice Yield over the twenty three regions of Bangladesh in 1971-80 and 1981-90. 


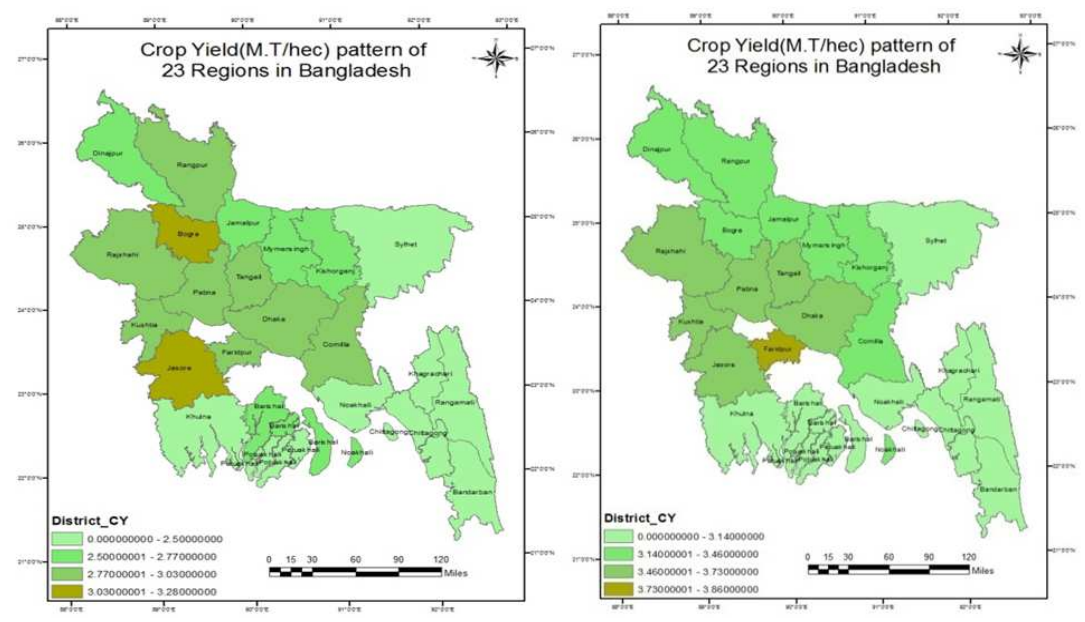

Figure 10: Boro Rice Yield over the twenty three regions of Bangladesh 1991-00 and 2000-08.

\subsection{Effect of Temperature \& rainfall on Crop yield}

This study aims of achieving a database and pattern that will be helpful to the decision making of Boro Rice Cultivation. That is why Boro yield data was prioritized above all. However, Boro production has increased over the years due to advancement in irrigation techniques, invention of High Yielding Variety of rice. Moreover, irrigation area for Boro rice has been changing due to river erosion, sedimentation, floods, land acquisition for development projects, resettlement issues etc. Thus, it is really difficult to state that effect of climate change is the only predominant impact on Boro cultivation.
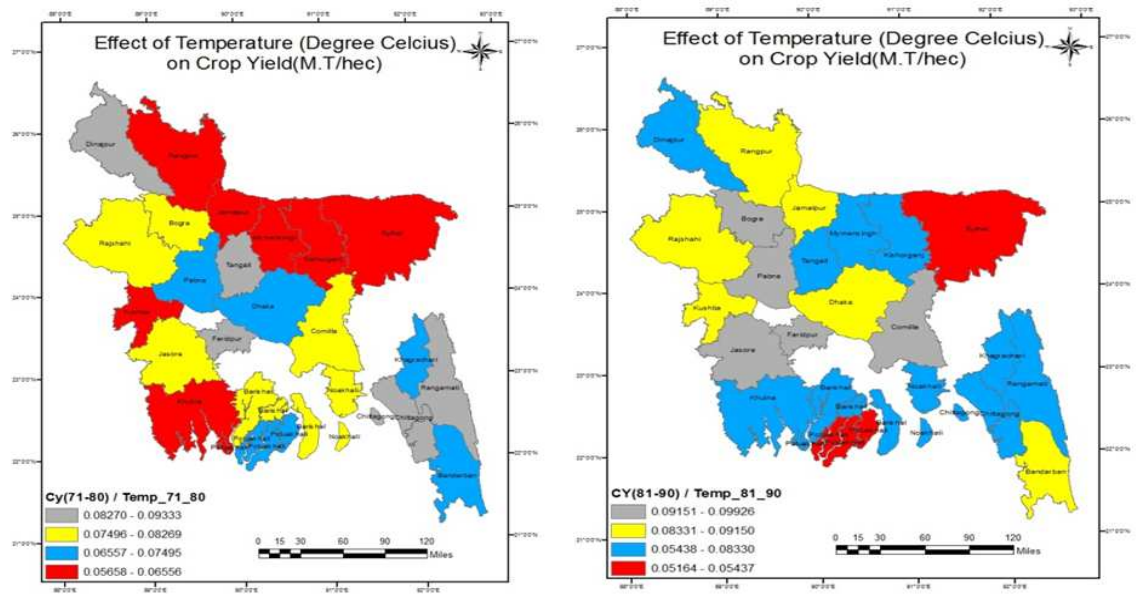

Figure 11: Effect of Temperature on Boro Yield (1971-80 and 1981-90)
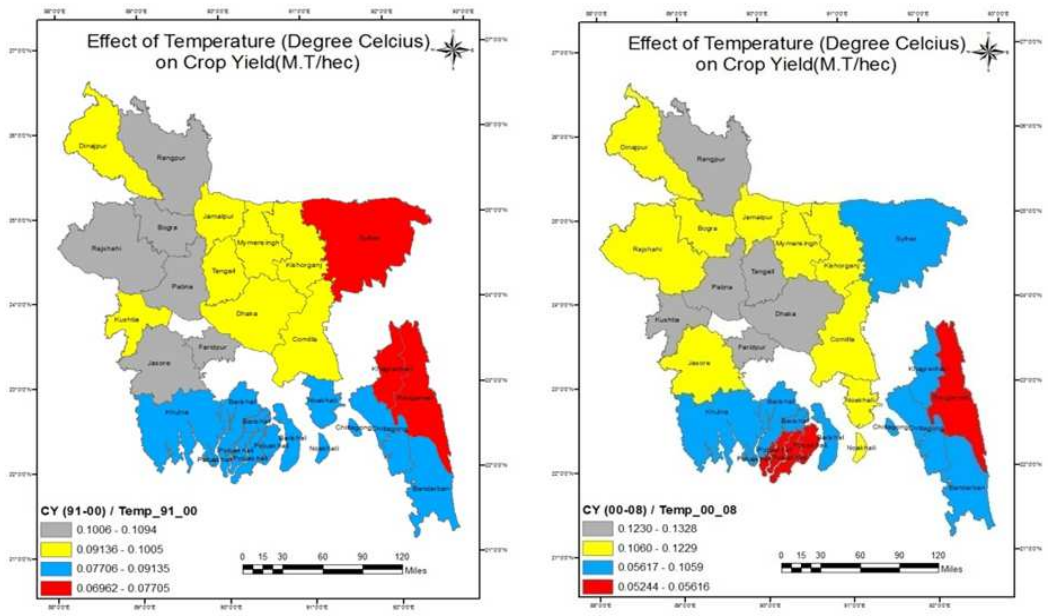

Figure 12: Effect of Temperature on Boro Yield (1991-00 and 2000-08) 


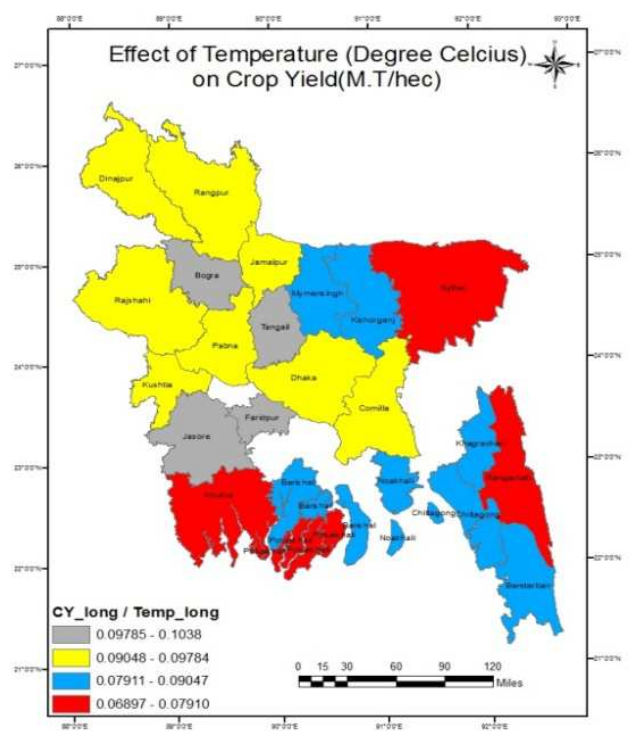

Figure 13: long term temperature effects on Crop yield
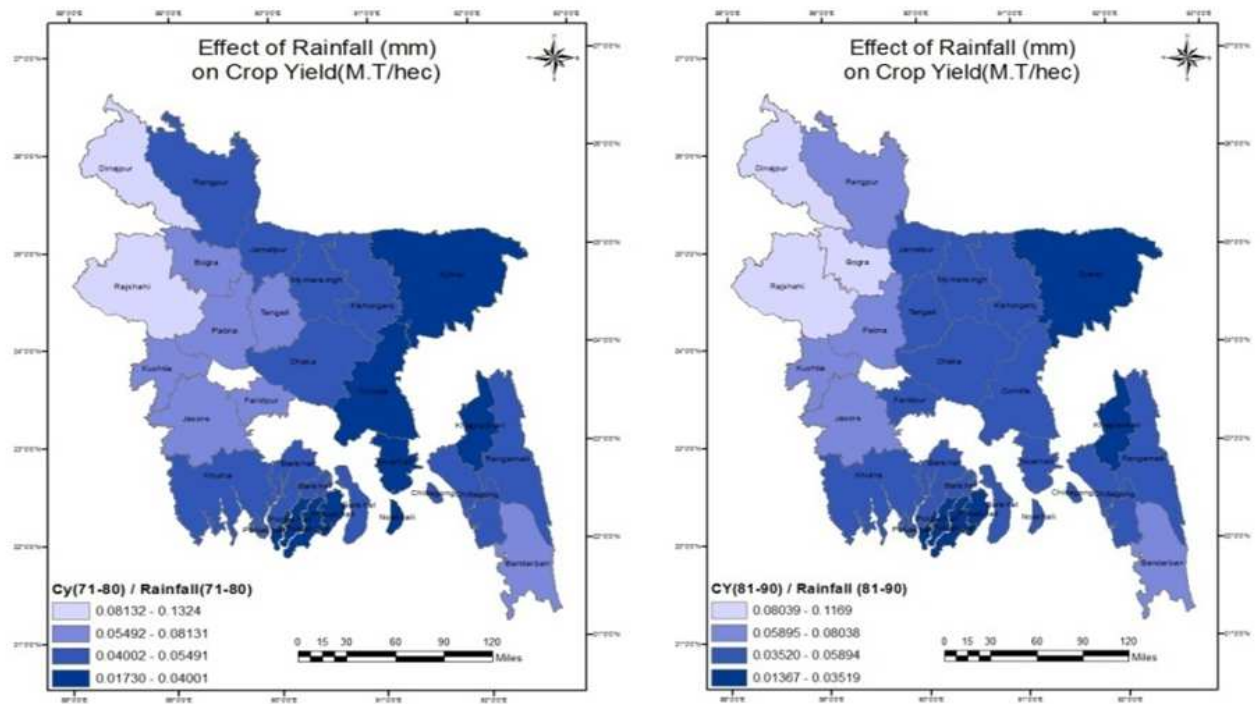

Figure 14: Effect of Rainfall on Boro Yield (1971-80 and 1981-90)
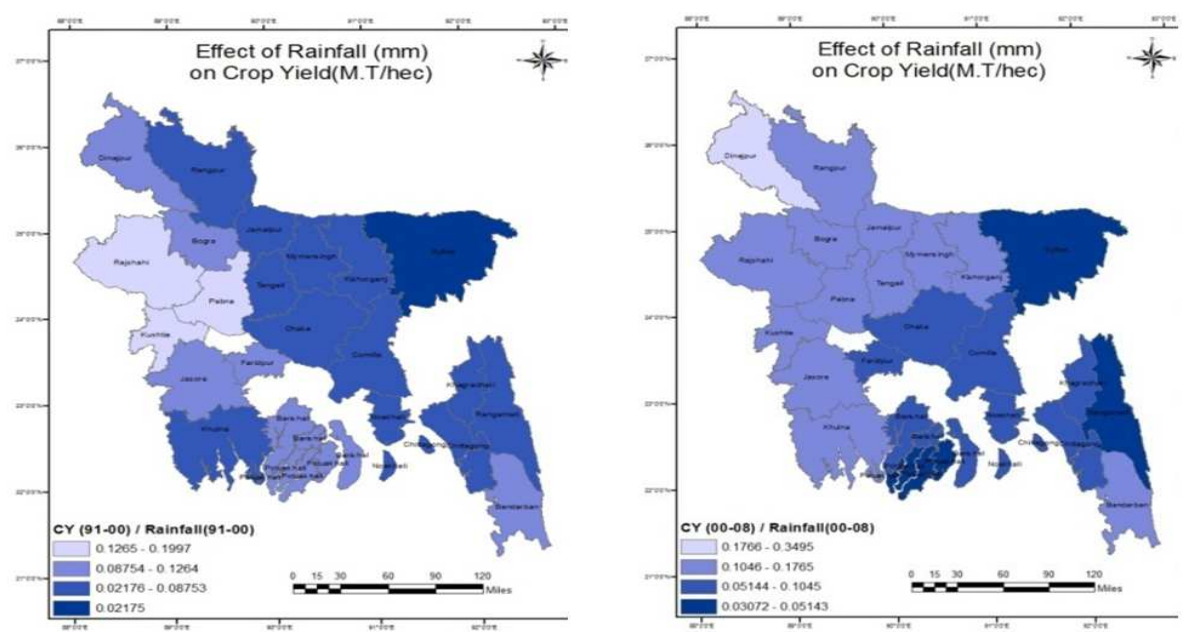

Figure 15: Effect of Rainfall on Boro Yield (1991-00) and (2000-08) 
There is totally different situation considering the effect of rainfall on crop yield. Mostly the eastern of the country has the higher crop yield and the effect is lower in that region (both in short term and long term). In all periods the western part is mostly effected region on the basis of rainfall.

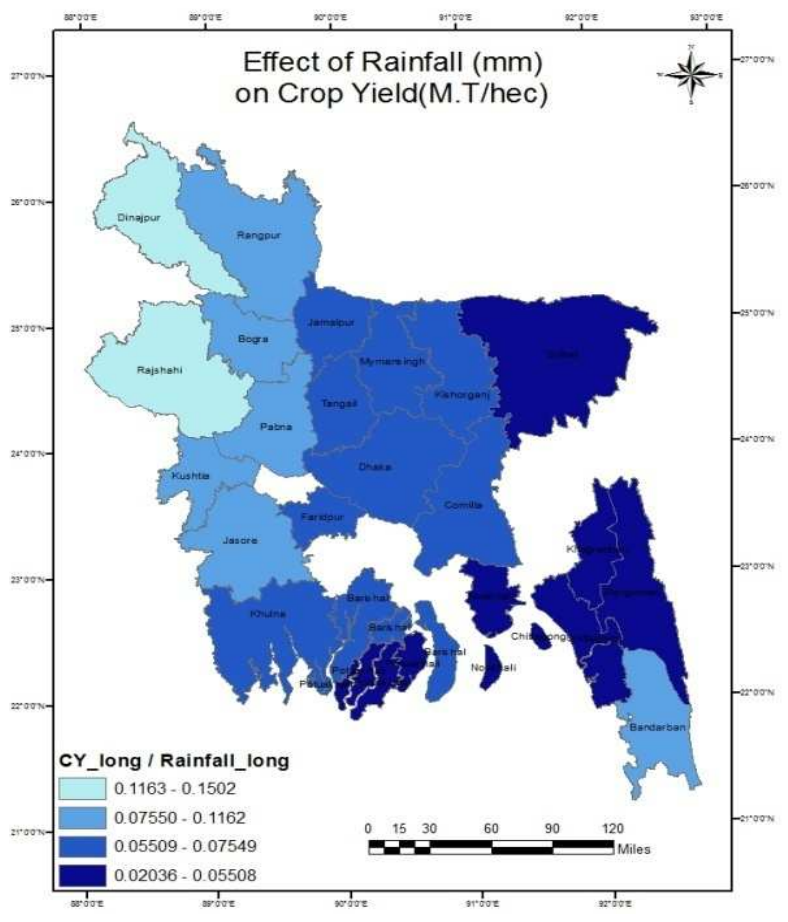

Figure 16: long term Rainfall effects on Crop yield

\section{Conclusion}

This study is limited to the analysis of historical data of climatic parameters. The effect of soil parameters on Boro rice is not considered here. Notwithstanding this fact, following conclusion has been made:

- $\quad$ Temperature \& rainfall vary separately from place to place. Moreover, they vary altogether for different places. So, it is very difficult to predict the overall impact on a broad area such as Bangladesh.

- In the 1971-1980 decade, Sylhet region has experienced very high rainfall and except Noakhali and Barderban, all other south-eastern regions have average rainfall ranging from 30 to $55 \mathrm{~mm}$. But during the year 1981-1990, rainfall increased and most of the zones with low rainfall became regions of average rainfall, whereas Dhaka and Faridpur along with Chittagong, Bandarban regions became regions of high rainfall. Year 1991-2000 follows almost same trend of rainfall pattern and in some regions (Pabna, Kushtia and Jessore) rainfall decreased from average to low. But in recent year, it is quite visible that rainfall reduced all over the 22 regions except Sylhet, where the rainfall was high throughout this 40 years' time frame.

\section{Recommendations}

Due to limited scope of this study, following recommendations are provided for future study-

- Parameters of Soil characteristics should be included.

- Boro rice has many varieties. So effect on each variety can be estimated by considering characteristics of each variety.

- Application of some model to predict future yield of boro rice can be incorporated to ensure food security.

- Other climatic parameters, such as $\mathrm{CO}_{2}$ emissions should be considered while assessing the climate change effect.

\section{References}

[1] Ahmed, A. and Ryosuke, S. 2000. Climate change and agricultural food production of Bangladesh: an impact assessment using GIS-based biophysical crop simulation model. Center for Spatial Information Science, University of Tokyo, 4-6-1 Komaba, Japan.

[2] BADC. 2009. Minor Irrigation Survey Report 2008-09. Dhaka: Bangladesh Agricultural Development Corporation (BADC), Ministry of Agriculture (MoA).

[3] Bangladesh Economics Review, 2009. Government of the People's Republic of Bangladesh. Ministry of Finance, Dhaka.

[4] BBS (Bangladesh Bureau of Statistics). 1975-2007.

[5] Biswas J.K. 2009. Personal communication with Jiban Krishna Biswas, Chief Scientific Officer, BRRI, Gazipur, Bangladesh.

[6] Choudhury, M. 2004. Climatic variables and itsimpact on some major agricultural crops ofBangladesh, M. S Thesis, Dept. Env. Sci.,Bangladesh Agric. Univ., Mymensingh.

[7] Mondal MH (2010). Crop agriculture of Bangladesh: Challenges and opportunities. Bangladesh J. Agric. Res., 35(2): 235-245.

[8] Year Book of Agricultural Statistics ofBangladesh. Stat. Div. Minis. Planning Govt.People's Repub. Bangladesh. 